\title{
Abnormal electromyographic activity of the urethral sphincter, voiding dysfunction, and polycystic ovaries: A new syndrome?
}

\author{
Clare J Fowler, Timothy J Christmas, Christopher R Chapple, Helen Fitzmaurice Parkhouse, \\ Roger S Kirby, Howard S Jacobs
}

\begin{abstract}
A potential association between abnormal electromyographic activity - that is, decelerating bursts and complex repetitive discharges - of the urethral sphincter and difficulty in voiding was examined in 57 women with urinary retention. Abnormal electromyographic activity was found in 33 . Ultrasonography of the ovaries in 22 of the 33 women showed that 14 had polycystic ovaries. Of the other eight women, two had had oophorectomies, one had shrunken ovaries and ovarian failure, and one had previously undergone oophorectomy and the other ovary could not be seen; in one neither ovary could be seen, and three had ovaries of normal appearance, although two of these women were taking the contraceptive pill. Thirteen of the group had endocrine symptoms and signs characteristic of the polycystic ovary syndrome. Videocystometrography in 17 of the women who were examined by ultrasonography showed low flow rates and high residual volumes of urine after micturition in 12 women who could void, the other five having chronic urinary retention.

A speculative hypothesis for the observed association of impaired voiding, abnormal electromyographic activity of the urinary sphincter, and polycystic ovaries is advanced, based on the relative progesterone deficiency that characterises the polycystic ovary syndrome. Progesterone stabilises membranes, and its depletion might permit ephaptic transmission of impulses between muscle fibres in the muscle of the urethral sphincter, giving rise to the abnormal electromyographic activity. This may impair relaxation of the sphincter, resulting in low flow rates of urine, incomplete emptying of the bladder, and, finally, urinary retention.
\end{abstract}

Departments of Clinical Neurophysiology and Urology, Middlesex Hospital, London WIN 8AA

Clare J Fowler, MRCP, consultant

Timothy J Christmas, FRCS, research registrar Christopher J Chapple, FRCS, senior registrar

Helen Fitzmaurice

Parkhouse, FRCS, research registrar

Roger S Kirby, FRCS, senior registrar

\section{Department of}

Reproductive

Endocrinology, University

College and Middlesex

School of Medicine,

London W1N 8AA

Howard S Jacobs, FRCP, professor

Correspondence to Dr Clare J Fowler, Department of Clinical Neurophysiology, Middlesex Hospital, London WIN 8AA.

\section{Introduction}

Abnormal electromyographic activity of the urethral sphincter (that is, decelerating bursts and complex repetitive discharges) has been described in women with retention of urine. ${ }^{1-3}$ Detailed analysis showed that it is typical of the type of repetitive, circuitous, self excitatory activity that results from ephaptic excitation between muscle fibres. ${ }^{2}$ Such abnormal activity has been suggested to prevent adequate relaxation of the sphincter during voiding, causing outflow obstruction of the bladder, an increased residual volume of urine, and eventually failure of the detrusor. ${ }^{12}$

Early in the course of investigating urinary retention in women by electromyography of the urethral sphincter we observed that a particular facies recurred, two women having typical features of the SteinLeventhal syndrome. An association of abnormal electromyographic activity, impaired sphincter relaxation, and ovarian dysfunction was suspected, and ovarian ultrasonography was performed when possible in subsequent cases. On reviewing the literature an obscure report was found of two cases of "psychogenic urinary retention" occurring after laparotomy, at which cysts on the ovaries were the only abnormal finding. ${ }^{4}$

Polycystic ovaries have several features that are conspicuous on both histological examination and high resolution ultrasonography; they are larger (mean volume $11 \cdot 2 \mathrm{ml}(95 \%$ confidence interval $10 \cdot 7$ to $11 \cdot 7)$ ) than normal ovaries (mean volume $5 \cdot 8 \mathrm{ml}(4 \cdot 6$ to $7 \cdot 3)$ ), with a highly echogenic and dense central stroma and numerous $(>10)$ peripherally located cysts of 4-6 mm in diameter. ${ }^{5}$ When associated with hirsutism, greasy skin, obesity, menstrual irregularity, and infertility the polycystic ovary syndrome may be the diagnosis. ${ }^{6}$ This condition is associated with increased concentrations of circulating androgens and luteinising hormone (with normal concentrations of follicle stimulating hormone) and, in 30\% of cases, hyperprolactinaemia and occurs in $25 \%$ of women with amenorrhoea and $90 \%$ of those with hirsutism.

\section{Patients and methods}

Fifty seven women with difficulties in voiding were referred to the department of clinical neurophysiology at the Middlesex Hospital during 1982-8 for electromyography of the urethral sphincter. The indication was retention of urine or dysfunction of voiding. The referring doctors were aware of our interest in the electromyographic abnormality, ${ }^{\prime}$ and patients were clearly selected.

Each patient underwent electromyography of the urethral sphincter with a concentric needle electrode, ${ }^{9-11}$ and abnormal electromyographic activity (that is, decelerating bursts and complex repetitive discharges) was found in 33. Pelvic ultrasonography was carried out in 22 of the 33 women (the other 11 , who had been early subjects and as secondary referrals from long distances could not be readily recalled, were not available). Ultrasonography was performed by one of two experienced radiographers with a $3 \mathrm{MHz}$ long focused transducer attached to an Aloka 720 high resolution sector scanner. A history of pelvic operations or menstrual irregularity and the presence of hirsutism or acne were recorded.

\section{Results}

In 33 women electromyography of the urethral sphincter showed profuse spontaneous decelerating bursts and complex repetitive discharges. Brief bursts of this type of electromyographic activity can occasionally be induced in the muscle of the urethral sphincter by movement of the needle, and a requirement for considering that the activity was abnormal was that it was widespread and spontaneous.

Fourteen of the women presented with urinary retention, 17 with difficulty in voiding, and two with overflow incontinence. Urodynamic studies were carried out in 17 women, and obstruction at the region of the striated sphincter was observed in all 12 who could still void. Instability of the detrusor was shown in four, a hypocontractile detrusor in three, and apparently normal detrusor function in 10 .

Of the 22 patients who had pelvic ultrasonography, 14 showed the characteristic features of polycystic ovaries. Of the eight remaining women, two had had bilateral oophorectomies; one had had a unilateral oophorectomy for ovarian cysts, and the other ovary could not be seen on ultrasonography; one had shrunken ovaries caused by premature ovarian failure; and in another neither ovary could be seen; in three the ovaries appeared normal, although two of these women were taking the contraceptive pill. In the 22 women a 
history of menstrual irregularity was recorded in 13, hirsutism in seven, and acne or greasy skin in seven (table I).

Endocrine assays were performed in nine of the patients (table II). Serum testosterone concentrations (mean $2.7 \mathrm{nmol} / \mathrm{l}$ ) were at or above the upper limit of the normal range $(0.5-2.5 \mathrm{nmol} / \mathrm{l})$ in seven of the patients. Serum concentration of luteinising hormone was above the normal range (5-12 $\mathrm{U} / \mathrm{l})$ in four of the patients (mean $15 \cdot 4 \mathrm{U} / 1$, range $3 \cdot 6-43 \cdot 8 \mathrm{U} / \mathrm{l}$ ). In all eight patients tested serum concentration of follicle stimulating hormone was within normal limits $(1 \cdot 0-4 \cdot 0 \mathrm{U} / 1)$. The serum prolactin concentration was above the normal upper limit $(700 \mathrm{mU} / \mathrm{l})$ in two patients.

TABLE I-Characteristics of the women with difficulties in voiding, abnormal responses on electromyography, and polycystic ovaries

\begin{tabular}{cccccc}
\hline Case No & $\begin{array}{c}\text { Age } \\
\text { (years) }\end{array}$ & $\begin{array}{c}\text { Duration of } \\
\text { symptoms (years) }\end{array}$ & Symptoms & $\begin{array}{c}\text { Rate of urine flow } \\
\text { (ml/s) }\end{array}$ & Urodynamic findings \\
\hline 1 & 37 & 8 & Difficulty in voiding & 12 & Instability of detrusor \\
2 & 34 & 11 & Difficulty in voiding & & Failure of detrusor \\
Stable detrusor \\
3 & 21 & 11 & Difficulty in voiding & 15 & Instability of detrusor \\
4 & 27 & 14 & Difficulty in voiding & 9 & Stable detrusor \\
5 & 39 & 5 & Difficulty in voiding & 12 & Stable detrusor \\
6 & 46 & 12 & Difficulty in voiding & 9 & Stable detrusor \\
7 & 21 & 4 & Urinary retention & 8 & Stable detrusor \\
8 & 27 & 2 & Urinary retention & & Failure of detrusor \\
9 & 45 & 10 & Urinary retention & 7 & Instability of detrusor \\
10 & 32 & 13 & Urinary retention & & Failure of detrusor \\
11 & 33 & 12 & Urinary retention & & Instability of detrusor \\
12 & 34 & 11 & Urinary retention & & Stable detrusor \\
13 & 23 & 7 & Urinary retention & & Stable detrusor \\
14 & 23 & 12 & Urinary retention & &
\end{tabular}

TABLE II - Hormonal profile of women with abnormal responses on electromyography and polycystic ovaries

\begin{tabular}{|c|c|c|c|c|c|}
\hline Case No & Symptoms & $\begin{array}{l}\text { Weight/ } \\
\text { (height) }^{2}\end{array}$ & $\begin{array}{c}\text { Testosterone } \\
(\mathrm{nmol} / \mathrm{l})\end{array}$ & $\begin{array}{l}\text { Luteinising } \\
\text { hormone } \\
\text { (U/l) }\end{array}$ & $\begin{array}{c}\text { Prolactin } \\
(\mathrm{mU} / \mathrm{l})\end{array}$ \\
\hline 1 & Oligomenorrhoea & $21 \cdot 6$ & & & \\
\hline 2 & Acne, hirsutism, amenorrhoea & & & & $718 \cdot 0$ \\
\hline 3 & Hirsutism & $19 \cdot 4$ & $2 \cdot 5$ & $6 \cdot 0$ & $505 \cdot 0$ \\
\hline 4 & Acne, hirsutism, amenorrhoea & 21.8 & 3.6 & $43 \cdot 8$ & $296 \cdot 0$ \\
\hline 5 * & & $22 \cdot 8$ & & & \\
\hline 6 & Menorrhagia & $24 \cdot 7$ & & & \\
\hline 7 & Acne, hirsutism, oligomenorrhoea & $21 \cdot 3$ & $3 \cdot 3$ & $13 \cdot 7$ & $736 \cdot 0$ \\
\hline 8 & Acne, hirsutism & $19 \cdot 7$ & 1.6 & $9 \cdot 0$ & \\
\hline 9 & Oligomenorrhoea & $23 \cdot 7$ & & & \\
\hline 10 & Menorrhagia, hirsutism, & $21 \cdot 7$ & & & \\
\hline 11 & Oligomenorrhoea & & $2 \cdot 6$ & 11.6 & $316 \cdot 0$ \\
\hline 12 & Acne, hirsutism, oligomenorrhoea & $21 \cdot 0$ & $3 \cdot 3$ & $19 \cdot 0$ & $296 \cdot 0$ \\
\hline 13 & Oligomenorrhoea & 28.6 & $2 \cdot 5$ & $12 \cdot 5$ & \\
\hline 14 & Acne & $20 \cdot 8$ & $2 \cdot 5$ & $7 \cdot 3$ & $373 \cdot 0$ \\
\hline
\end{tabular}

«Symptoms not known.

Five women were treated with cyproterone and ethinyloestradiol. ${ }^{12}$ Despite improvement in their skin they did not notice any lasting improvement in their urinary symptoms. Six were treated with phenytoin, but none reported any symptomatic benefit. Urethral dilatation under general anaesthesia was similarly of no long term benefit in nine patients, and those with retention continued to be optimally managed by clean intermittent self catheterisation.

\section{Discussion}

We have reported abnormal electromyographic activity in women with urinary retention and now describe a further seven cases in which there was outflow obstruction but as yet no detrusor failure. An apparent association of abnormal electromyographic activity, impaired relaxation of the striated urethral sphincter, and polycystic ovaries is reported here for the first time.

Other workers have recorded the same type of abnormal electromyographic activity in the urethral sphincter in disorders of bladder function other than urinary retention. Butler described pseudomyotonia of the periurethral sphincter in three women with stress incontinence. ${ }^{13}$ Potenzoni et al described pseudo- myotonia in nine women with dissimilar anatomical and clinical conditions, two of whom had established multiple sclerosis and bladder dysfunction, one a spinal cyst, and another spina bifida. ${ }^{14}$ Dyro et al, identifying the activity as complex repetitive discharges rather than pseudomyotonia (a subtle point of electromyographic nomenclature ${ }^{2}$ ) reported its presence in 26 patients in a paediatric practice who had presented with urinary complaints, both in the context of neurological disorders and as isolated symptoms. ${ }^{\text {is }}$ Eleven of these patients had myelodysplasia; 12 others had either incontinence or recurrent infections without evident neurological abnormality, and, notably, all of these were female. We have observed this type of activity in two patients not included in this series, both of whom had well documented evidence of neurological disease, one having established multiple sclerosis with typical changes on magnetic resonance imaging and the other a prolapse of the S1 central disc, which was shown radiologically and treated by operation. In both patients urinary retention was a prominent symptom. Thus the full meaning of the abnormal electromyographic response is not completely understood. There seem to be two broad groups of patients with such a response, those with myelodysplasia and others, exclusively female patients, who present with differing types of urinary complaint. Here, however, we emphasise the high incidence of this finding in women without established neurological disease but who have severe dysfunction in voiding for which no alternative explanation has been found.

Sixty four per cent of the present group of women with an abnormal electromyographic response and impaired outflow had polycystic ovaries. Indeed, polycystic ovaries were absent in only three women who had ultrasonography, two of whom were taking oral contraceptives. The group was characterised by a remarkable prevalence of ovarian disturbances, as shown either by a history of ovarian operation or by a combination of characteristic ultrasound findings with the clinical features of the Stein-Leventhal syndrome (that is, menstrual irregularity with hyperandrogenisation). Polycystic ovaries are found commonly in women with amenorrhoea (25\%), oligomenorrhoea $(85 \%)$, or hirsutism $(90 \%) .{ }^{8} \mathrm{~A}$ recent study has described a $22 \%$ prevalence in a volunteer population. ${ }^{16}$ Although remarkably high, this prevalence is far lower than that in our patients. Moreover, bladder function has not been studied in women with the polycystic ovary syndrome.

The abnormal activity that can be recorded from the urethral sphincter is confined to that muscle, and the patients show no other symptoms or signs suggesting a more generalised neuromuscular disorder. An explanation for this highly localised abnormality must be conjectural, but the association with polycystic ovaries now seems to be so strong that an endocrinological basis seems probable.

Sexual differentiation of the musculature of the pelvic floor has been described morphometrically, the type 1 fibres of the anal sphincter being smaller than the type II fibres in women. The converse of this applies to the fibres of skeletal musculature, type I fibres being normally about $10 \mu \mathrm{m}$ larger than type II fibres. ${ }^{17}$ The striated muscle of the urethral sphincter differs in some respects from skeletal striated muscle. An immunohistochemical study by Crowe $e t$ al showed that the striated muscle fibres of the urethral sphincter were surrounded by an unusual ring of material positive for vasoactive intestinal polypeptide. ${ }^{18}$ Thus the possibility exists that some hormonally peculiar feature of this muscle renders it alone susceptible to developing abnormal electromyelographic activity.

The endocrinological findings in the polycystic ovary syndrome are characterised by high concentra- 
tions of circulating androgens and oestrogens and, when the patients are anovulatory, by a relative deficiency of progesterone. Progesterone has a stabilising effect on membranes. Perhaps reduced stability of membranes in the muscle of the urethral sphincter allows circuitous excitatory pathways between muscle fibres to be established. The suggestion that progesterone deficiency is important remains speculative, particularly because anovulatory menstrual cycles are fairly common and this bladder disturbance is unusual: the high levels of androgens in the polycystic ovary syndrome are probably not important as this type of activity has not been found in men, even young men with unexplained obstructed voiding.

Electromyography of the urethral sphincter and its interpretation require some skill; if this is not available ovarian ultrasonography may contribute useful information about the pathogenesis of otherwise unexplained urinary retention in women.

We thank Mr R T Turner-Warwick, Mr E J G Milroy, Mr P H L Worth, Mr J L Osborne, Mr W F Hendry, and Mr S J Steele for allowing us to study their patients, and Ms J Adams and her colleagues, whose skill in ultrasonography formed an essential part of the study.

1 Fowler CJ, Kirby RS. Abnormal electromyographic activity (decelerating burst and complex repetitive discharges) in the striated muscle of the urethral sphincter in 5 women with persisting urinary retention. $\mathrm{Br} f \mathrm{Urol}$ 1985;57:69-70

2 Fowler CJ, Kirby RS, Harrison MJG. Decelerating burst and complex repetitive discharges in the striated muscle of the urethral sphincter, associated with urinary retention in women. $\mathcal{F}$ Neurol Neurosurg Psychiatry $1985 ; 48: 1004-9$.

3 Fowler CJ, Kirby RS. Electromyography of urethral sphincter in women with urinary retention. Lancet 1986; ; 1455-6.

4 Allen TD. Psychogenic urinary retention. South Med f 1972;65:302-4

5 Adams J, Franks S, Polson DW, et al. Multifollicular ovaries: clinical and endocrine features and response to pulsatile gonadotrophin releasing hormone. Lancet 1985;ii:1375-8.

6 Franks S, Adams J, Mason H, Polson D. Ovulatory disorders in women with polycystic ovary syndrome. Clinics in Obstetrics and Gynaecology 1985;12 605-32.

7 Jacobs HS. Polycystic ovaries and polycystic ovary syndrome. Gynaecological Endocrinology 1987;1:113-31.

8 Adams J, Polson DW, Franks S. Prevalence of polycystic ovaries in women with anovulation and idiopathic hirsutism. Br Med f 1986;293:355-9.

9 Frankssen C, Petersen I. Investigation of disturbances in the striated muscle of the urethral sphincter. Br f Urol 1955;27:154-61.

10 Blaivas JG, Labib KL, Bauer SB, Retik AB. A new approach to electromyography of the external urethral sphincter. F Urol 1977;117:773-7.

11 Fowler CJ, Kirby RS, Harrison MJ, Milroy FJ, Turner-Warwick R. Individual motor unit analysis in the diagnosis of disorders of urethral sphincter innervation. F Neurol Neurosurg Psychiatry 1984;47:637-41.

12 Miller JA, Jacobs HS. Treatment of hirsutism and acne with cyproterone acetate. Clinics in Endocrinology and Metabolism 1986;15:373-89.

13 Butler WJ. Pseudomyotonia of the periurethral sphincter in women with urinary incontinence. $\mathcal{F}$ Urol 1979;122:838-40.

14 Potenzoni D, Juvarra G, Bettoni L, Stagha G. Pseudomyotonia of the striated urethral sphincter. F Urol 1983;130:512-3.

15 Dyro FM, Bauer SB, Hallett $M$, et al. Complex repetitive discharges in the external urethral sphincter in the pediatric population. Neurology and Urodynamics 1983;2:39-44.

16 Polson DW, Adams J, Wadsworth J, et al. Polycystic ovaries-a common finding in normal women. Lancet $1988 ; \mathrm{i}: 870-2$.

17 Beersiek F, Parks AG, Swash M. Pathogenesis of ano-rectal incontinence: a histometric study of the anal sphincter musculature. F Neurol Sci 1979;42: 111-27

18 Crowe R, Light JK, Chilton CP, Burnstock G. Vasoactive intestinal polypeptide (VIP)-immunoreactive nerve fibres associated with the striated muscle of the human external urethral sphincter. Lancet 1985;i:47-8.

(Accepted 20 September 1988)
Diabetes and Arthritis

Epidemiology Section and Epidemiology and Clinical Research Branch, National Institute of Diabetes and Digestive and Kidney

Diseases, National

Institutes of Health,

Phoenix, Arizona 85014,

United States

Mohammed F Saad, MD,

visiting associate

William C Knowler, MD,

chief of section

David J Pettitt, MD, assistant

chief of section

Robert G Nelson, MD, senior staff fellow

Peter H Bennett, MB, chief of

research branch

Correspondence to:

Dr Saad.

\title{
Transient impaired glucose tolerance in Pima Indians: Is it important?
}

\author{
Mohammed F Saad, William C Knowler, David J Pettitt, Robert G Nelson, Peter H Bennett
}

\section{Abstract}

As part of a continuing epidemiological study of noninsulin dependent diabetes among Pima Indians 154 subjects who had had a transient impairment of glucose tolerance were followed up for 1.2-16.9 (median 5.8) years after their glucose tolerance had returned to normal. Of these, 49 subsequently developed diabetes; 26 subsequently developed impaired glucose tolerance; and 79 had normal glucose tolerance at the last examination. The cumulative incidence of diabetes was $16 \%$ and $48 \%$ at five and $\mathbf{1 0}$ years of follow up respectively, compared with $3 \%$ and $8 \%$ for a control group of 1245 members of the same population. After adjustment for age, sex, body mass index, and plasma glucose concentration two hours after glucose loading the incidence of diabetes among the subjects who had had transient impaired glucose tolerance was $\mathbf{3 . 0}$ times that among the controls $(95 \%$ confidence interval $2 \cdot 1$ to $4 \cdot 3$ ). Proportional hazards function analysis indicated that obesity was the most important predictor of subsequent development of diabetes.

The results suggest that transient impairment of glucose tolerance indicates, at least in some subjects, a predisposition to diabetes and should not be considered clinically unimportant.

\section{Introduction}

The category impaired glucose tolerance was introduced in $1979^{1}$ and subsequently adopted by the World Health Organisation ${ }^{2}$ to include people who have glucose tolerance outside the normal range but not diagnostic of diabetes. Impaired glucose tolerance, however, is an unstable state. ${ }^{4}$ Riccardi et al reported that $34 \%$ of people with impaired glucose tolerance had normal glucose tolerance when tested again within two to four months. ${ }^{5}$ In several long term studies $24-53 \%$ of people who initially had impaired glucose tolerance had normal glucose tolerance within 10 years of follow up. ${ }^{6-9}$ Little is known, however, about the long term outcome in people with only a transient impairment of glucose tolerance. We report the outcome in 154 Pima Indians who had transient impaired glucose tolerance and were followed up for $1 \cdot 2-16 \cdot 9$ years after their glucose tolerance became normal.

\section{Subjects and methods}

We collected the data as part of a continuing epidemiological study of non-insulin dependent diabetes among Pima Indians who live in the Gila River Indian community in central Arizona. Subjects are examined biennially from the age of 5 . Each examination includes a medical history, a physical examination, and a modified oral glucose tolerance test in which a carbohydrate load equivalent to $75 \mathrm{~g}$ glucose is ingested after an overnight fast. In the early part of the study only plasma glucose concentration two hours after glucose loading was measured. Since 1975 fasting plasma glucose concentration has also been measured.

We studied 154 subjects with transient impaired glucose tolerance - that is, they had a plasma glucose concentration two hours after glucose loading of $7 \cdot 8$ $11 \cdot 1 \mathrm{mmol} / \mathrm{l}$; had had normal glucose tolerance (plasma glucose concentration at two hours $<7.8 \mathrm{mmol} / \mathrm{l}$ ) in al of the preceding examinations (median of two exami- 